\title{
Description of a new species of Acotyledon Oudemans (Acari: Acaridae) feeding on eggs of the Sitotroga cerealella (Olivier) (Lepidoptera: Gelechiidae), with a method for determining sex in deutonymphal stages
}

\author{
Sayed A. Eraky ${ }^{1}$; Azza, A. Mohamed ${ }^{2}$; Seham, A. Ezz El-Dein² \& Hosam, M. El-Gepaly ${ }^{2}$ \\ ${ }^{\text {I}}$ Plant Protection Department, Faculty of Agriculture, Assiut University, Assiut 71526 Egypt, E-mail,seraky53@yahoo.com. \\ ${ }^{2}$ Plant Protection Research Institute, Agricultural Research Center, Dokki, Giza, Egypt, E-mail, \\ azza.abdelgawad@yahoo.com
}

\section{ABSTRACT}

A new species, Acotyledon hookisetoses sp. nov. (Acari: Acaridae), collected from the stock colony of Sitotroga cerealella reared on wheat grains, is described, and illustrated from adults and deutonymphs. Sex-specific morphological differences at the deutonymphal stage are reported and discussed.

Keywords: Taxonomy, Acaridae, Astigmatina, immature stages, stored product.

\section{INTRODUCTION}

The genus Acotyledon Oudemans, 1903, inhabits a wide range of habitats. Oudemans founded it in1903, with Acotyledon paradoxa as the type species. Several researchers have made a good deal of research on mites of the genus Acotyledon in their respective areas (Mahunka 1961, 1973, 1974, 1978; Samsinak 1966, 1968; Fain and Philips 1978; Ashfaq and Chaudhri 1986; Ashfaq et al., 1998; Klimov 2000; Ashfaq and Sher 2002; Honey et al. 2014). In upper Egypt, a few species of the genus Acotyledon (i.e., A. lamiai Eraky 1998; A. manure Eraky 1999a; A. nerminka Eraky 1999a; A. longsetoses Eraky 1999b; A. ahmadi Eraky and Osman 2008 and A. shortisetoses Eraky et al. 2020) were described from the manure of animals and the termite nests based on deutonymphal stages (heteromorphic deutonymphs). The acarid mites of the genus Acotyledon, are serious pests of stored grains and stored products. They help to increase the infestations of bacteria and fungi in stores by raising the moisture content and adjusting the chemical composition of the grains, as well as to kill the seed germs and thus reduce the germination potential of the seeds. In Bio-LabShandaweel of Plant Protection Research Institute (PPRI), Agricultual Research Center (ARC), Egypt, the new species Acotyledon hookisetoses sp. nov. was found feeding on eggs of $S$. cerealella that were reared on wheat grains as a factitious host of an egg parasitoid, Trichogramma evanescens. The new species' economic importance stems primarily from its effect on the efficiency of $S$. cerealella egg production for mass rearing of the egg parasitoid. So that, the current study aimed to increase our knowledge about the acarid mite fauna in Egypt by describing a new species of Acotyledon. The adult and deutonymphal stages of the Acotyledon hookisetoses sp. nov. are described, in addition to sex-specific morphological differences at the deutonymphal stage are reported and discussed.

\section{MATERIALS AND METHODS}

The acarid mites of the genus Acotyledon are the serious pests of stored grains and stored products. This genus was erected by Oudemans, 1903 with Acotyledon paradoxaas its type species. The economic importance of the new mite species is due mainly to its effect on the efficiency of quantitative production of the Sitotroga cerealella (Olivier) (Lepidoptera: Gelechiidae) eggs used for mass rearing of the egg parasitoid, Trichogramma evanescens Westwood, 1833 (Hymenoptera: Trichogrammatidae). In Bio-Lab-Shandaweel, the laboratory stock colony of $A$. hookisetoses sp. nov. had enough mites at various developmental stages (females, males, and deutonymphs). The presence of deutonymphs in two sizes has been noted (small and large). As a result, 50 deutonymphs of large size were collected from the stock culture and separated into five groups, put in five Petri dishes (5 cm diameter), each dish containing 10 individuals was supplied with enough yeast as a source of food, and all dishes were tightly sealed with Parafilm to prevent mites from escaping. The small-sized deutonyphs were treated the same way as before. All small deutonymphs developed into tritonymphal stages and then adult males, while all large deutonymphs evolved into tritonymphal stages and then adult females after a few days. The adults and both deutonymphal stages were 
mounted on a glass slide. Measurements are in micrometers $(\mu)$. The new species' adults and deutonymphs were described and illustrated. The terminology and abbreviations for idiosomal chaetotaxy are based on Grandjean (1939) and Griffiths et al. (1990); for legs chaetotaxy; and Klimov \& O’Connor (2003) for organotaxy.

\section{RESULTS AND DISCUSSION}

\section{Taxonomy}

Cohort: Astigmatina (Astigmata) Canestrini, 1891. Superfamily: Acaroidea Latreille, 1802.

Family: Acaridae Latreille, 1802.

Genus: Acotyledon Oudemans, 1903.

Type species: Acotyledon paradoxa Oudemans, 1903.

\section{Acotyledon hookisetoses sp. nov.}

Description. Female (Figs. 1-11; $n=6$ ). The body is roughly oval. Idiosoma range for all types: 993 (928-1058) long; 798 (791-805) wide.

Dorsum (Figs. 1\&2): The prodorsal shield punctuate, almost rectangular, and has a slightly concave posterior margin. Internal vertical setae (vi) long, roughly spaced apart at the straight anterior margin of the prodorsal shield. External vertical setae (ve) are very short and situated along the lateral margins of the prodorsal shield about halfway. Internal scapular seta (sci) short, positioned behind prodorsal shield, on the same line of the external one (sce), the latter long, more than three times as long as the former. Basal lope of Grandjean's organ with one large, barbed tooth; Grandjean's organ (Fig. 5), 32 (31-33) long; supracoxal seta $(s c x)$ pectinate with about 5-7 branches medially on both lateral sides and broadly expanding from its base but gradually tapering distally (Figs. 2 \& 5). Idiosoma with 13 pairs of setae. Normal and filiform dorsal setae. Dorsal setae length: vi 95 (90-100); ve 11 (10-12); sci 83 (80-86); sce 270 (266-274); scx 39 (38-40); c1 49 (47-51); c2 61 (60-62); c3 46 (44-48); cp 62 (61-63); d1 116 (113-119); d2 91 (87-95); d3 111 (108-114); el 224 (220-228); e2 103 (95-111); f2 103 (97-109); hl 197 (195-199); h2 208 (200216); $h 3$ 192(191-193).

Gnathosoma (Fig. 3). 129 (120-138) long and 105 (98-112) wide; palp divided into two segments, palptarsus with a simple seta $(p t)$ and one solenidion $(\omega)$; palptibia with one simple seta $(d)$; basal part of palp fused to infracapitulum, bearing a simple lateral palpal supracoxal seta (elcp). Long, simple ventral seta on infracapitulum $(m)$. Chelicerae (Fig. 4), chelate, 129 (127-131) long, 57 (56-58) wide, with a small ventral seta (cha), spine-like, at the base of terminal digits. pt 18, $d$ 14, elcp 25, $m$ 44, cha 8; $\omega$ 8; gnathosomal setae length (in holotype).

Venter (Figs. 6-7). Legs coxae fused with idiosoma, each bounded by sclerotized apodeme. Coxal field I anterior apodemes wide and join at the midline to form a "Y-shaped" sternum. The latter short, ending free. Coxal field II, III, and IV anterior apodemes short, ending free, and not fused medially. Coxa I with a single seta (la), Coxa III with two setae ( $3 a$ and $3 b$ ), and Coxa IV with a single seta (4a). Among coxae III and IV, genital opening (Fig. 7) occurs, with two pairs of genital papillae protected by genital valves and one pair of genital setae $(g)$. The anal opening posterior to the genital opening, with six pairs of small setae, (ad3, ps3, ps2, ad2, ps1, ad1). Copulatory opening and spermatheca invisible. Length of setae: ventral setae: $1 a 31$ (29-33), $3 a$ 24 (23-25), $3 b 29$ (28-30), g 24 (22-26), $4 a 41$ (4042). Anal setae: ps1 15 (11-19), ps2 22 (18-26), ps3 22 (21-23), ad1 14 (10-18), ad2 9 (8-10), ad3 9 (8-10).

Legs (Figs. 8-11). All legs with broad and hooked empodial claw. Length of legs I-IV: I 321 (316325), II 309 (307-311), III 302 (294-310), IV 322 (315-329). Chaetotaxy: (solenidia and special setae in parentheses), trochanters 1-1-1-0, femora $1-1-0-1$, genua $2(2 \sigma)-2(1 \sigma)-1(1 \sigma)-0$, tibiae $2(1 \varphi)-$ $2(1 \varphi)-1(1 \varphi)-1(1 \varphi)$, tarsi $11(3 \omega, 1 \varepsilon)-10(1 \omega)-7-8$. Measurements of leg setae and solenidia as follows: Leg I (Fig. 8): $p R 28$ (26-30), $v F 93$ (84102), cG 34 (31-37), $m G 49$ (43-55), ol 29 (2830), o2 64 (61-67), gT 28 (23-33), hT 25 (19-31), $\varphi 130$ (126-134), $\varepsilon 12$ (11-13), $\omega 118$ (17-19), $\omega 2$ 8 (8-8), w3 25 (23-27), ba 7 (6-8), aa 25 (23-27), wa 25 (22-28), la 26 (23-29), ra 50 (47-53), d 54 (50-58), f 33 (30-36), e 18 (17-19), q 20 (18-22), u 8 (8-8), p 8 (7-9). All setae and solenidia on leg I filiform, except $c G, g T, h T, b a, w a, l a, e, q, p, u$ spine-like. $\omega 1$ cylindrical, $\sigma 1$ and $\sigma 2$ curved and tapering. Leg II (Fig. 9); $p R 28$ (25-31), $v F 104$ (99-109), cG 39 (39-39), mG 39 (38-40), o32 (31-

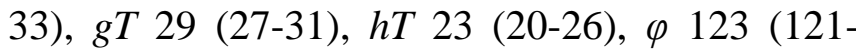


125), $\omega 17$ (16-18), ba 26 (22-30), aa 21(20-22), wa 18 (16-20), la 24 (23-25), ra 39 (36-42), d 56 (50-62), $f 40$ (35-45), e 22 (20-24), q 17 (16-18), $u$ 7 (6-8); setae $g T, h T, a a, b a, w a, e, l a, q, u$ spinelike. solenidium $\omega$ cylindrical, $\varphi$ very long and filiform; setae $p R, v F, c G, m G, a a, r a, d, f$ and $\sigma$ filiform. Leg III (Fig. 10): $s R 29$ (27-31). $n G 48$ (46-50), $\sigma$ 23(21-25), $k T 31$ (31-31), $\varphi 105$ (99-
111), w 28 (21-35), r33 (32-34), d 71 (70-72), e 22 (20-24), $f 49$ (48-50), $p 14$ (13-15), q 28 (2630); $s R, n G, \sigma, \varphi, r, d, f$ filiform; $k T, e, p, q, w$ spine-like. Leg IV (Fig. 11): $w F 33$ (32-34), $k T 27$ (25-29), $\varphi 69$ (62-76), $f 44$ (40-48), $d 80$ (76-84), filiform; setae $r 31$ (30-32), w 25 (23-27), e 19 (19-19), p16 (14-18), и 8 (7-9), q 18 (16-20), spine-like.

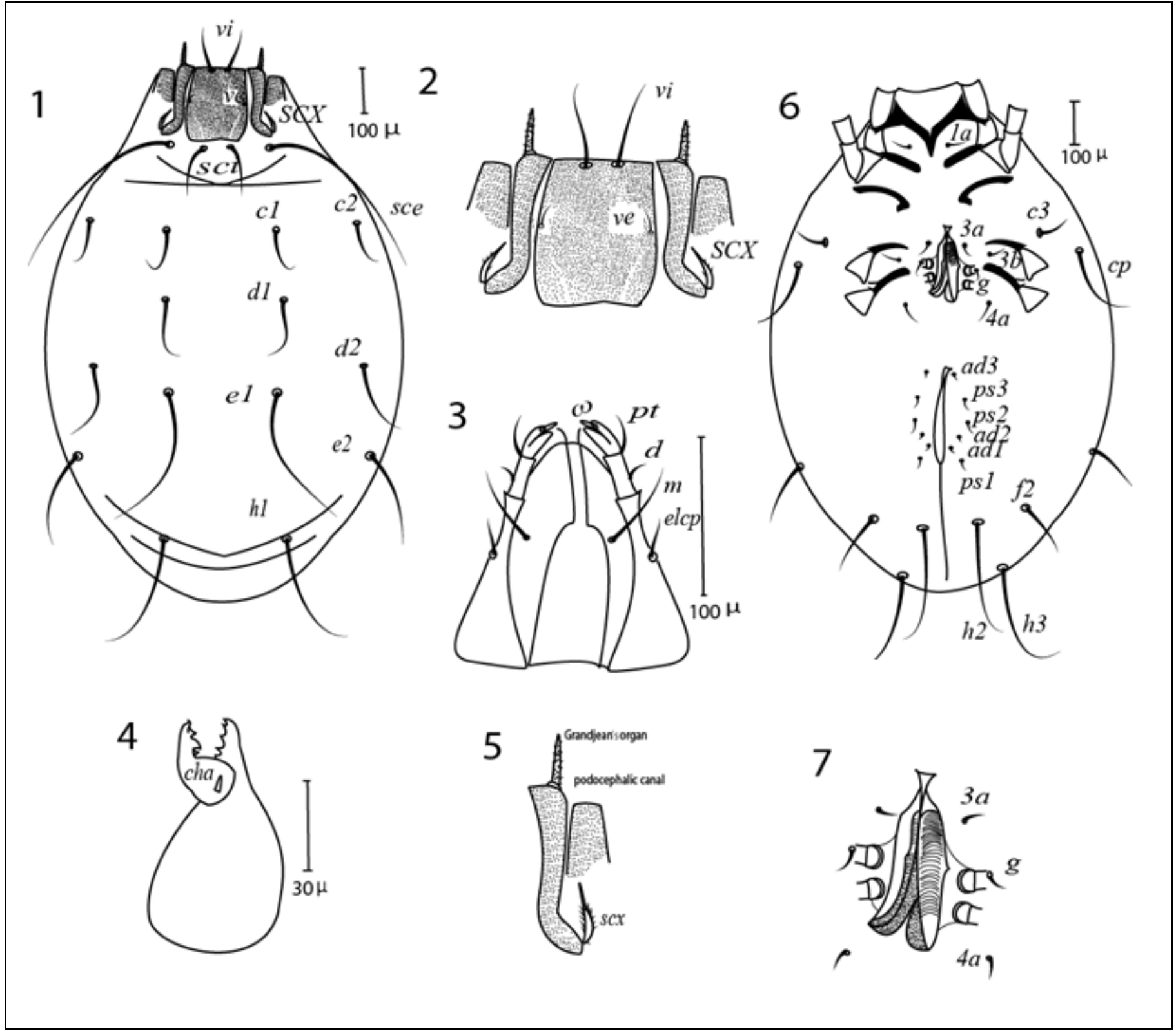

Figures (1-7). Acotyledon hookisetoses sp. nov. (adult female): 1. Dorsal view; 2. Prodorsal shield; 3. Gnathsoma; 4. Chelicera; 5. Grandjean's organ; 6. Ventral view; 7. Genital region. 


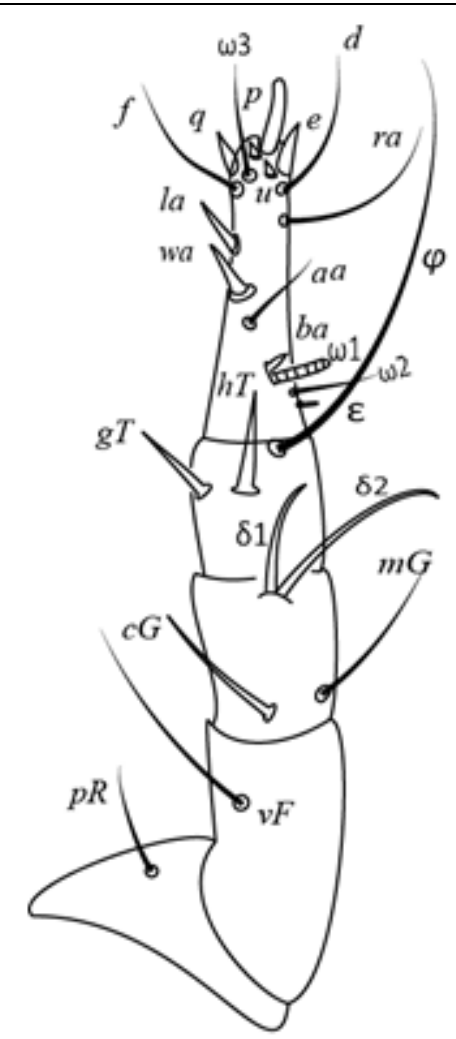

8

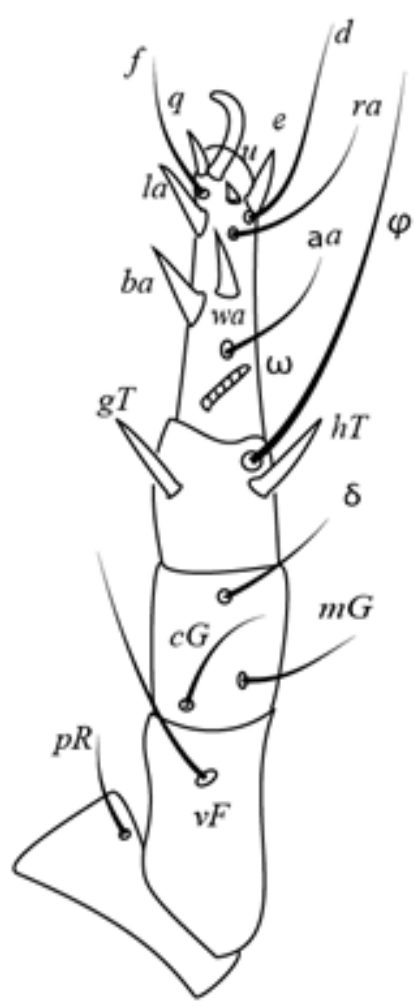

9

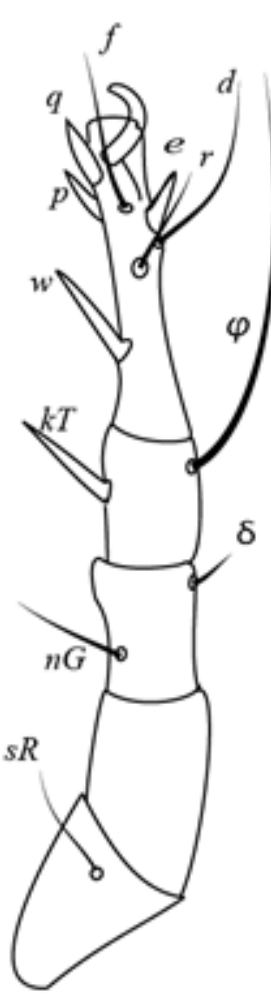

10

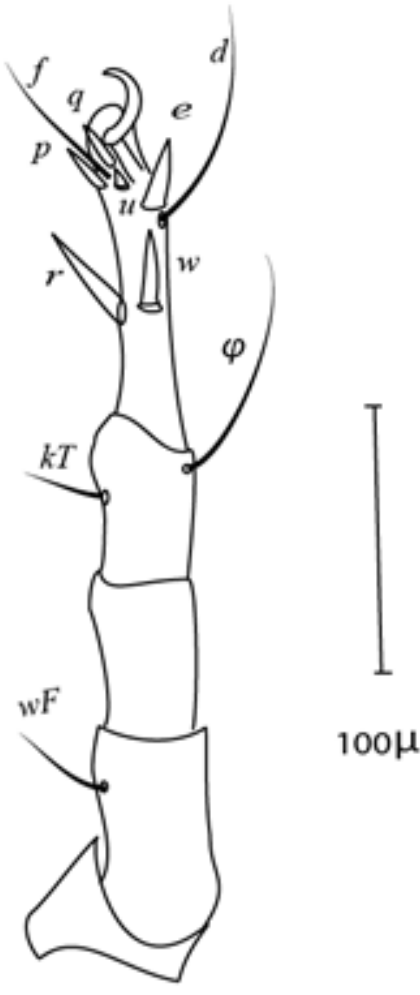

11

Figures (8-11). Acotyledon hookisetoses sp. nov. (adult female): 8. Leg I; 9. Leg II; 10. Leg III; 11. Leg IV.

Description. Male (Figs. 12-23; $n=6$ ) Body approximately oval. Idiosoma 623 (613-633) long, 416 (408-424) wide.

Dorsum (Fig.12). Prodorsal shield (Fig. 15) punctuate almost rectangular shape with posteriorly emarginated and slightly concaved in both lateral margins. Internal vertical setae ( $v i)$ long and thick, situated at the concaved anterior margin of prodorsal shield, approximately close to each other. External vertical setae (ve) very short and thin situated about halfway along lateral margins. Internal scapular seta (sci) long, but shorter than seta (sce), positioned behind prodorsal shield, at the same line of the external one (sce), the latter long, about twice as long as the former; basal lope of Grandjean's organ with one large, barbed tooth; Grandjean's organ (Fig. 19), 16 (1517) long; supracoxal seta (scx), pectinated with about 5-7 branches medially on both lateral sides and broadly expanding from its base but gradually tapering distally. Idiosoma with 13 pairs of setae. All dorsal setae long and filiform, the posterior ones whip-like. Length of dorsal setae: vi 125
(120-130); ve 16 (12-20); sci 108 (106-110); sce 207 (200-214); scx 36 (34-38); c1 71 (67-75); c2 99 (96-102); c3 234 (230-238); cp 70 (68-72); d1 137 (130-144); d2 140 (135-145); el 266 (262270); f2 206 (200-212); h1 307 (305-309); h2 264 (260-268); h3 333 (300-306).

Gnathosoma (Fig. 16). 107 (105-109) long and 79 (77-81) wide; palp divided into two segments, palp tarsus with a simple seta $(p t)$ and one short and thin solenidion $(\omega)$; palp tibia with one simple seta $(d)$; basal part of palp fused to infracapitulum, palpal supracoxal seta (elcp) invisible. Infracapitulum with long, simple ventral seta $(m)$. Chelicerae (Fig. 14). Length: 123 (120-126) long, 44 (42-46) wide, chelicerae chelate, having a small ventral seta (cha), spine-like, positioned at the base of terminal digits. Length of gnathosomal setae (in holotype): pt 18, $d 14, m$ 41, elcp 19, cha 6 ; solenidion $\omega 7$.

Venter (Fig. 13). Legs coxae fused with idiosoma, each bounded by a sclerotised apodeme. Anterior apodemes of coxal field I broad, jointed at the midline to form "Y-shaped" sternum. The latter 
short, ending free. Anterior apodemes of coxal field II, III, and IV well-developed but also short, ending free, not fused medially. A pair of thick sclerotized sejugal apodemes presented between coxae II and III. Coxa I with one seta $(1 a)$, coxa III with two setae ( $3 a$ and $3 b$ ), and coxa IV with one seta $(4 a)$. Genital region (between coxae IV), with two pairs of genital papillae covered by genital valves and one pair of genital setae $(g)$ (Fig. 18). Anal region (Fig. 17) positioned posterior to genital opening, with three pairs of pseudo anal setae ( $p s 1, p s 2, p s 3)$, setae ps1 longer than $p s 3$; $p s 2$ vestigial, only alveoli present. Anal region with a pair of anal suckers and a pair of anal discs. Length of ventral setae: Setae $1 a 47$ (45-49), 3a 20 (17-23). 3b 61 (58-64), g41 (3943), $4 a 58$ (55-61); ps156 (52-60), ps3 21 (19-24).

Legs (Figs. 20-23). All legs with normal and hooked empodial claw, Length of legs I-IV: I 352 (340-364), II 363(356-370), III 367 (360-374), IV 376 (369-383). Chaetotaxy of leg segments I-IV (trochanter-tarsus) as follows (solenidia and special setae in parentheses): trochanters 1-1-1-0;

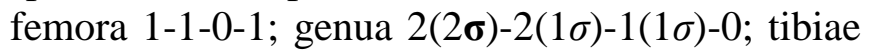
$2(1 \varphi)-2(1 \varphi)-1(1 \varphi)-1(1 \varphi)$; tarsi $12(3 \omega, 1 \varepsilon)-11$

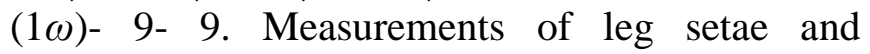
solenidia as follows: Leg I (Fig. 20): $p R 42$ (4044), $v F 84$ (83-85), cG 51 (48-54), $m G 51$ (50-52), ol43 (42-44), o278 (69-87), gT 26(23-29), hT31 (29-33), $\varphi 118$ (112-124), \& 11 (10-12), $\omega 114$ (1315), $\omega 226$ (23-29), $\omega 315$ (13-17), ba6 (5-7), aa 45 (42-48), wa 28 (24-32), la 26 (23-29), ra 70 (66-74), $d 46$ (41-51), f 34 (30-38), e 15 (14-16), q 5 (4-6), u 6 (5-7), p6 (5-7), s 8 (7-9). All setae on leg I spine-like, except $p R, v F, c G, m G, a a, r a, f, d$ filiform; solenidia $\omega 1-3, \varepsilon$ very short and slightly widen basally and tapering apically; solenidia $\sigma l-2$, $\varphi$ long and filiform. Leg II (Fig. 21): $p R 57$ (5361), $v F 108$ (101-115), $c G 48$ (45-51), $m G 55$ (5159), $\sigma$ 50(42-58), gT 30 (28-32), hT 33 (30-66), $\varphi$ 105 (102-108), w 23 (19-27), ba 27 (24-30), wa 26 (22-30), la 54 (50-58), ra 40 (36-44), d 56 (50-62), f 54 (53-55), e 34 (30-38), p 12 (10-14), q 10 (713), u 8 (7-9), s 14 (10-18); setae $g T, h T, b a$, wa, $e, q, u, p, s$ spine-like and the rest setae filiform; solenidion $\omega$ cylindrical and slightly tapering apically, $\varphi$ very long and filiform, $\sigma$ short and filiform. Leg III (Fig. 22): $s R 80$ (76-84). $n G 64$ (59-69), $\sigma 16(15-17), k T 44$ (36-52), $\varphi 119$ (110128), w56 (52-60), r 33 (31-35), d62 (58-66), e 28
(25-31), f85 (80-90), s 28 (25-31), p8 (7-9), q18 (16-20), u 8 (7-9); setae $k T, w, r, e, q, u, p, s$ spine-like; the rest setae and solenidia filiform. Leg IV (Fig. 23): $w F 56$ (52-60), kT 29 (25-33), $\varphi 28$ (27-29, d72 (66-78), e 26 (24-28), u 9 (7-11), p 20 (17-23), q 9 (8-10), s 33 (30-36), r 42 (4044), w 38 (34-42); setae kT, r, w, p, q,e, s, u spiniform, the rest setae and solenidium filiform $(w F, d, \varphi)$.

Description. Deutonymphs (Figs. 24-39)

Deutonymphal female (Figs. 24-31). Body approximately ovoid, wide in the middle; idiosomal 275 (267-283) long, 225 (218-232) wide $(\mathrm{n}=6)$. Gnathosoma (Fig. 25). Infracapitulum of gnathosoma pear-shaped, length 22 (21-23), width 11 (10-12); palps short, but well separated off 7 (68) long, 3 (2-4) wide; palpal supracoxal setae (elcp) 7 (6-8) long, simple, and filiform; apical palpal solenidion $(\omega) 40(38-42)$ long, stout, and filiform; infracapitular setae $(m) 13$ (11-15) long, thick, and filiform.

Dorsum (Fig. 24). Idiosoma smooth, without any sculptures. Both anterior and posterior margins of propodosoma concaved. Dorsosejugal region smooth, tight laterally, and wide medially. A pair of oval cupules ia situated laterally between setae $c 2$ and $c p$, a pair of oval cupules im placed between setae $d 3$ and $e 2$, cupules ip invisible. All idiosomal setae thin and hook-like. Internal vertical setae $v i$ 13 (11-15), external ones ve invisible. Measurements of dorsal setae are presented in Table (1).

Venter (Fig. 26). Apodemes I located posterior to infracapitulum of gnathosoma, fused forming a long sternum, the latter free posteriorly; anterior apodemes II extending postero-medially but ending free posteriorly; posterior apodemes II long fused posteriorly but not fused with anterior ones; anterior apodemes of coxal field III long, medially fused by thin apodemes, the posterior ones free anteriorly; anterior apodemes of coxal field IV fused medially and to longitudinal posterior sternal apodeme, the latter long fused anteriorly, thus coxal fields I, II, III open, coxal field IV closed. Coxal fields I and III, each with normal circular discs $(1 a, 3 b)$ and coxal fields IV with the largest ones (4a) and small alveoli (3a) located medially on the end of posterior apodemes III; genital setae (g) 11 (10-12) long, positioned anterior and medial to $4 a$. Adhering plate (Fig. 27), 45 (40-50) long, 44 
(42-46) wide, normal-developed, filling a space between legs IV, positioned on more distant far from posterior body margin; central suckers large approximately circular, with broad margin surrounded a pair of small suckers, anterior suckers smaller than central ones, approximately oblong, consisting of broad sclerotized margin surrounding a normal disc. Lateral and posterior suckers normal-developed. Away from suckers, adhering plate internally punctuated.

Legs (Figs. 28-31). All legs with well-developed hooked empodial claws, arising apically. Length of legs: legs I 96 (90-102), legs II 85 (81-89), legs III 94 (90-98), legs IV 100 (96-104). Trochanters I, II, and III each with filiform setae ( $p R$ I, pR II, $s R$ III). Femoral setation: 1-1-0-1, setae $v F$ I, $v F$ II and $w F$ IV, filiform. Genual setation: $2(\sigma)-2(\sigma)-$ 1-0; setae $c G$ I and II, both spine-like, setae $m G$ I, II and $n G$ III filiform. Tibial setation: $2(\varphi)-2(\varphi)-$ $1(\varphi)-1(\varphi)$; setae $g T, h T$ legs I and II, spine-like; setae kT legs III and IV short and filiform; solenidia $\varphi$ of legs I-IV, filiform, very long on both legs I and II. Tarsal setation: $7(\omega 1, \omega 2)-6$ $(\omega)$-8-8. Setae $q$ tarsi I and $d$ tarsi II, uncate-like, other setae on tarsi I-IV, filiform, except setae $e$ on tarsi I, with crescent-like apices; solenidia $\omega l$ on tarsi I long, striped and tapering, solenidia $\omega$ on tarsi II, slightly shorter, but at the same look of $\omega 1$ on tarsi I; solenidia $\omega 2$ on tarsi I very short and tapering; $\varepsilon$ tarsi I and II, absent. Measurements of leg setation (I-IV) are presented in Table (2).

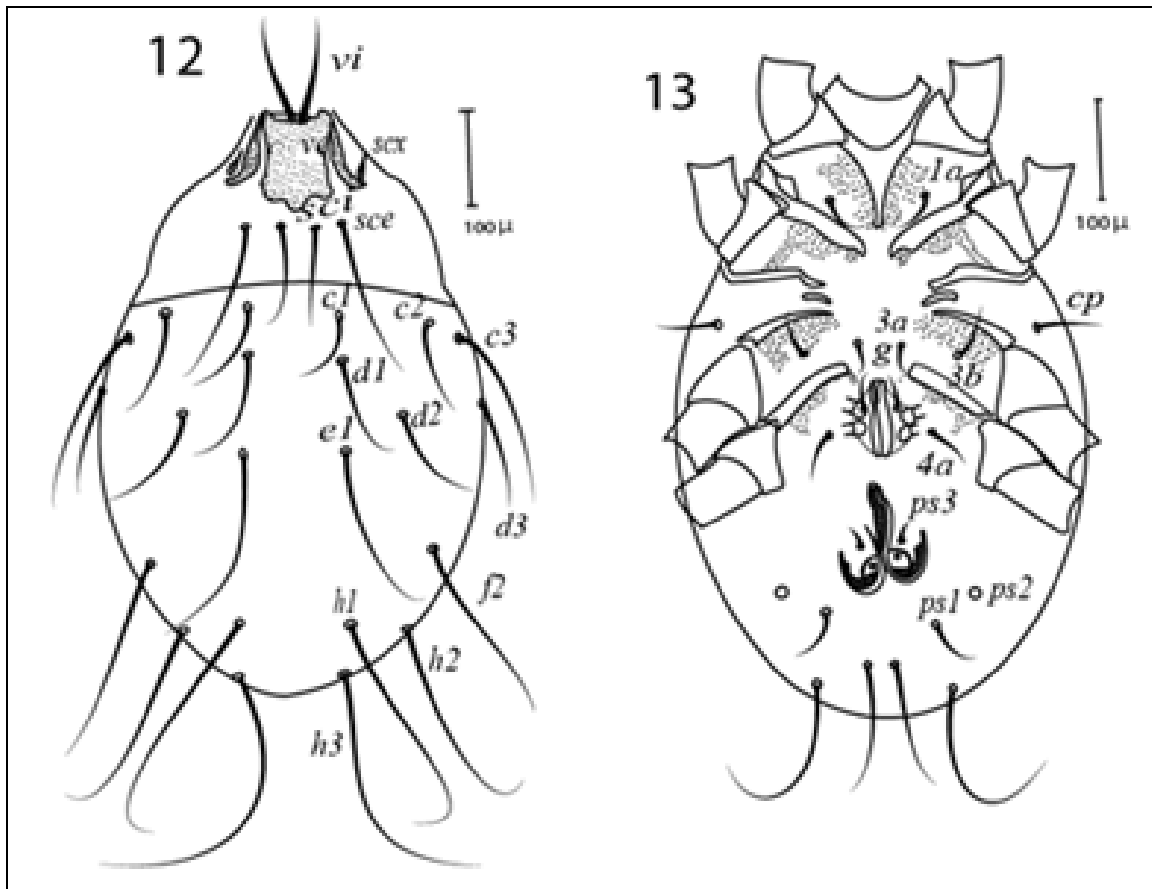

14

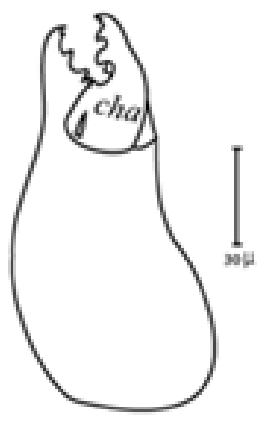

17

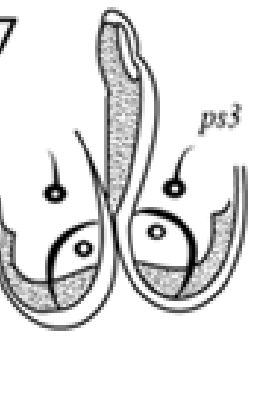

18

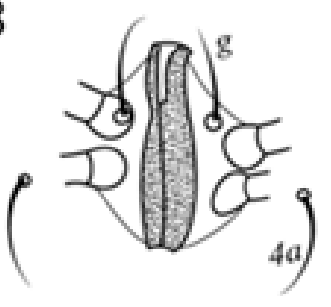

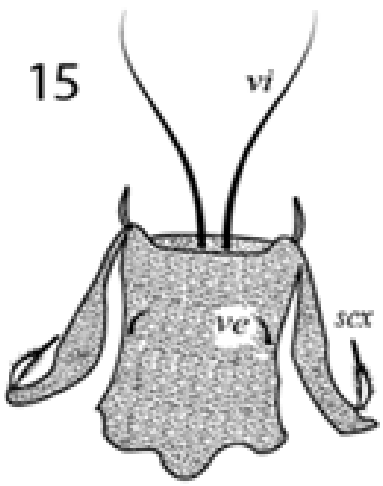

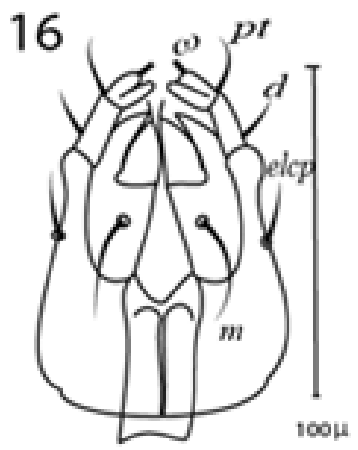

19

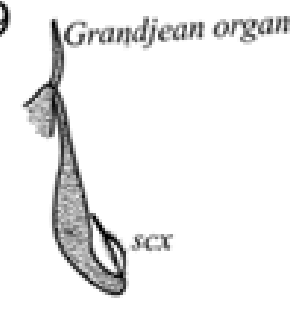

Figures (12-19). Acotyledon hookisetoses sp. nov. (adult male): 12. Dorsal view; 13. Ventral view; 14. Chelicera; 15. Prodorsal shield; 16. Gnathsoma; 17. Anal region; 18. Genital region; 19. Grandjean's organ. 


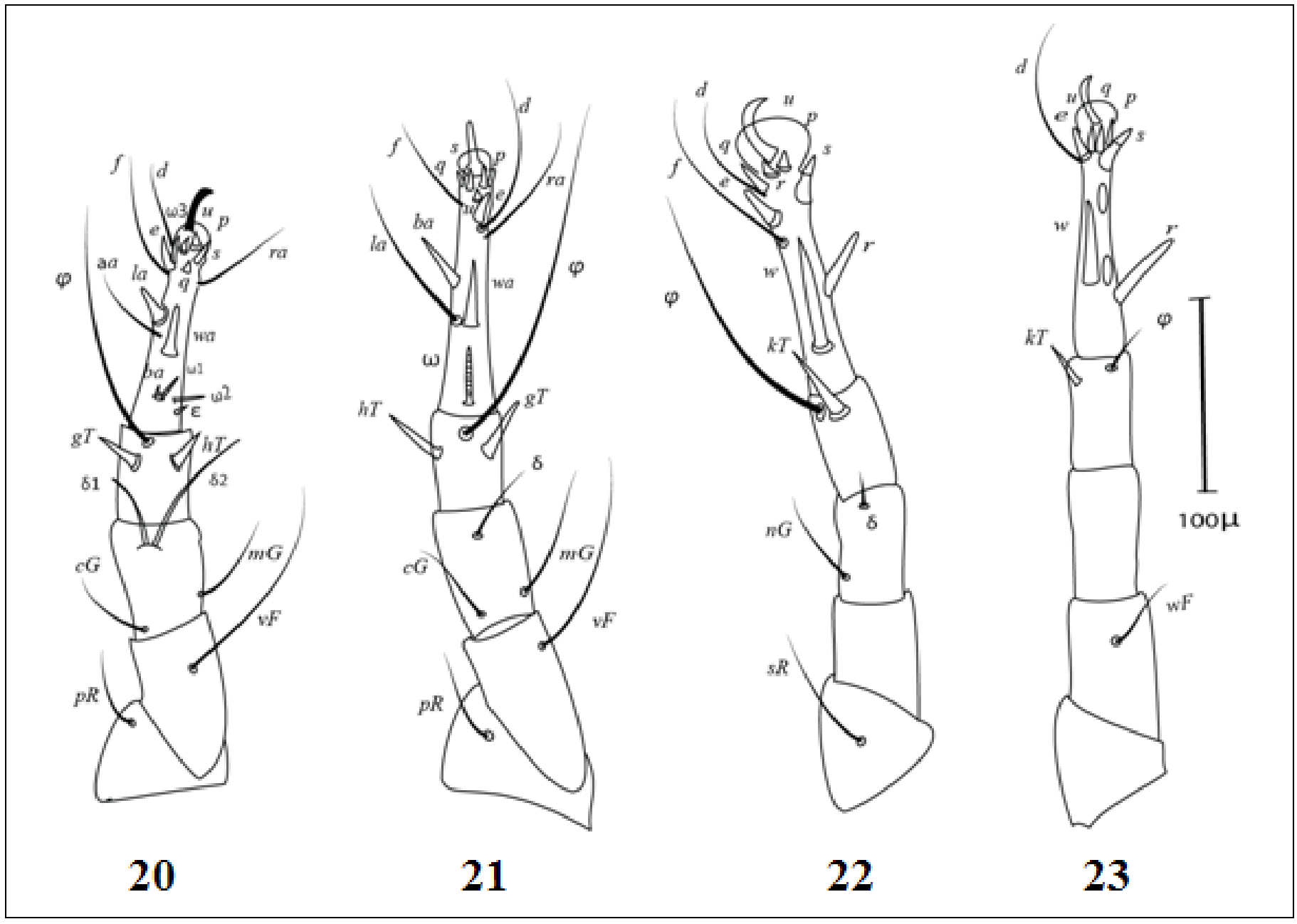

Figures (20-23). Acotyledon hookisetoses sp. nov. (adult male): 20. Leg I; 21. Leg II; 22. Leg III; 23. Leg IV.
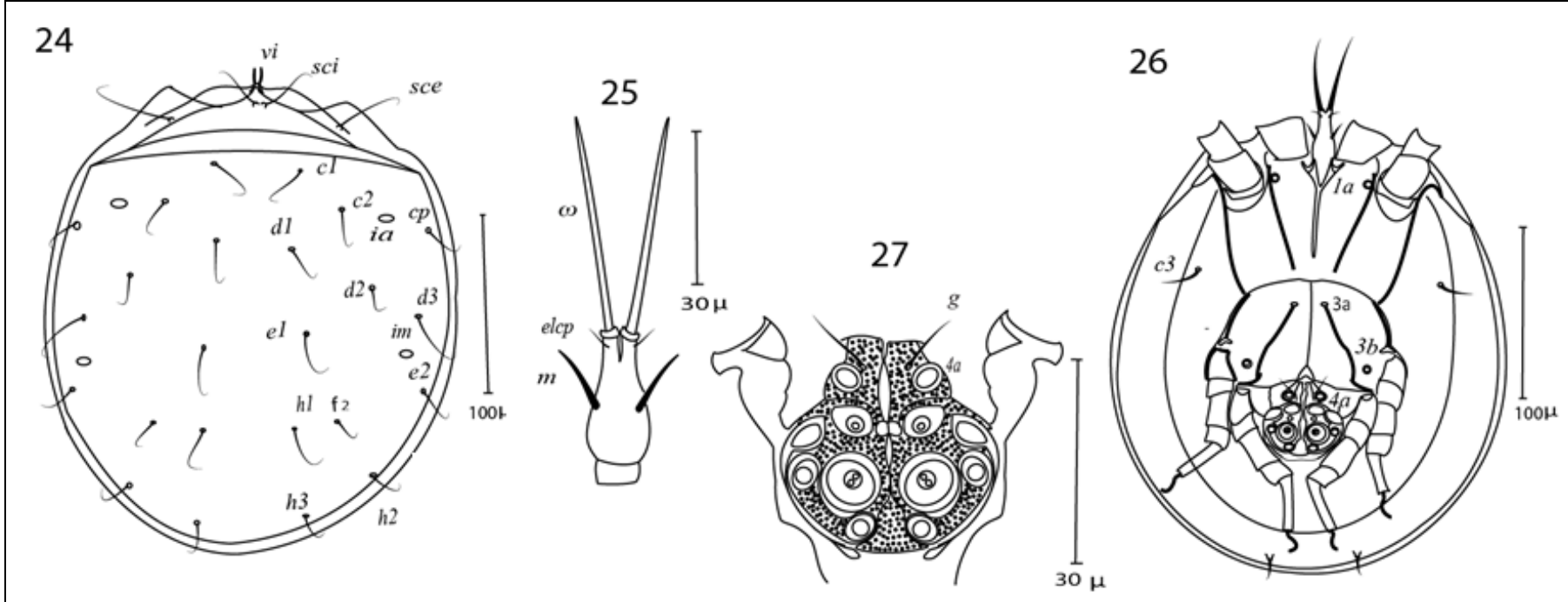

Figures (24-27). Acotyledon hookisetoses sp. nov. (deutonymphal female): 24. Dorsal view; 25. Gnathosoma; 14. Ventral view; 27. Adhering plate. 


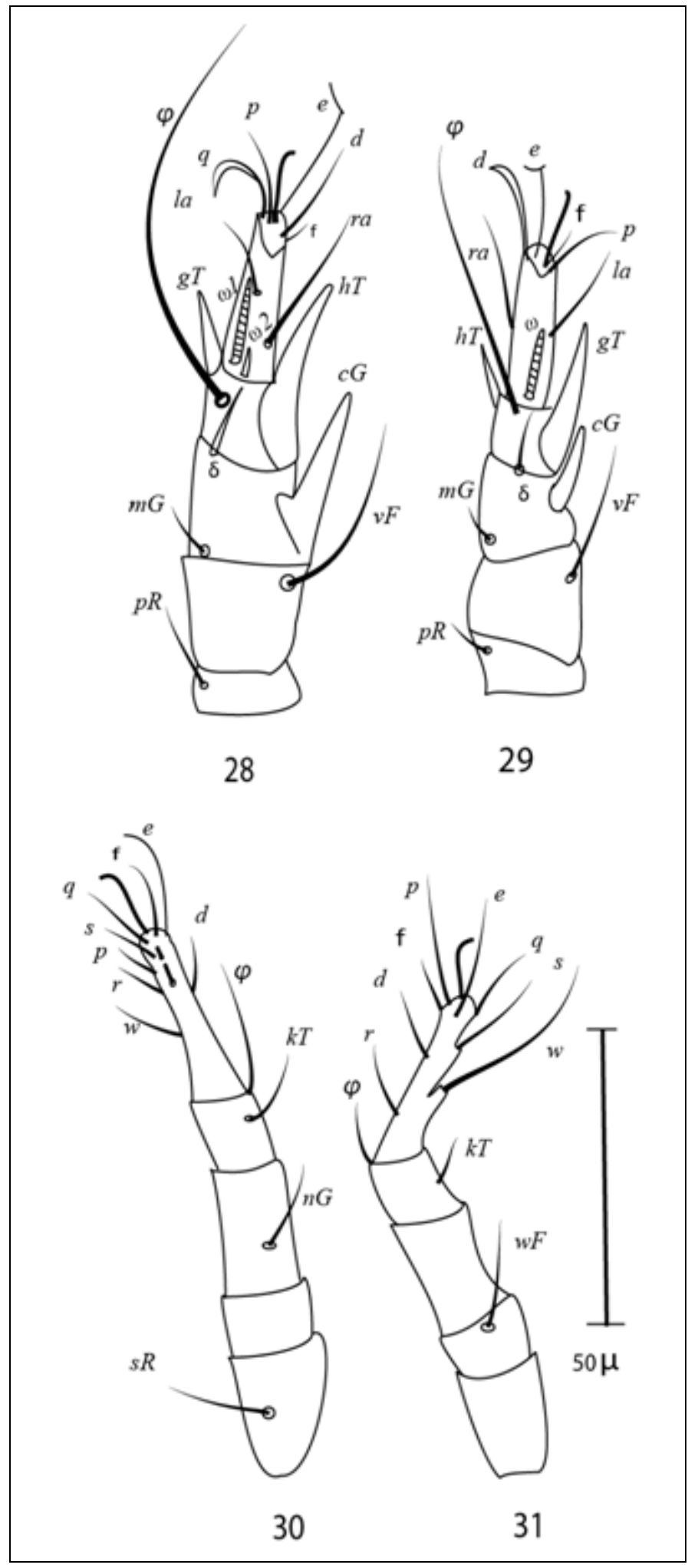

Figures (28-31). Acotyledon hookisetoses sp. nov. (deutonymphal female): 28. Leg I; 29. Leg II; 30. Leg III; 31. Leg IV.
Table 1. Measurements of idiosomal setae of Acotyledon hookisetoses sp. nov. (deutonymphal stages, $\mathrm{n}=6$ ).

\begin{tabular}{ccc}
\hline $\begin{array}{c}\text { Idiosomal } \\
\text { setae }\end{array}$ & $\begin{array}{c}\text { Deutonymphal } \\
\text { female }\end{array}$ & $\begin{array}{c}\text { Deutonymphal } \\
\text { male }\end{array}$ \\
\hline$s c i$ & $36(33-39)$ & $20(16-24)$ \\
$s c e$ & $33(30-36)$ & $28(27-29)$ \\
$c 1$ & $29(27-31)$ & $18(15-21)$ \\
$c 2$ & $18(17-19)$ & Alveoli \\
$c 3$ & $19(18-20)$ & present \\
$c p$ & $15(14-16)$ & $18(15-21)$ \\
$d 1$ & $28(26-30)$ & $12(10-14)$ \\
$d 2$ & $23(22-24)$ & $19(16-22)$ \\
$d 3$ & $21(18-24)$ & $13(11-15)$ \\
$e 1$ & $25(22-28)$ & $15(12-18)$ \\
$e 2$ & $22(19-25)$ & $19(19-19)$ \\
$f 2$ & $18(17-19)$ & $14(13-15)$ \\
$h 1$ & $23(20-26)$ & $13(10-16)$ \\
$h 2$ & $20(17-23)$ & $20(17-23)$ \\
$h 3$ & $15(12-18)$ & $16(13-19)$ \\
& & $15(13-17)$ \\
\hline
\end{tabular}

Deutonymphal male (Figs. 32-39). Body approximately ovoid, wide in the middle; idiosomal length: 202 (188-216); width 165 (157173) $(n=6)$. Gnathosoma (Fig. 33): Infracapitulum of gnathosoma pear-shaped, length 17 (16-18), width 9 (8-10); palps short, but well separated off 4 (4-4) long, 2 (2-2) wide; palpal supra coxal setae (elcp) 5 (4-6) long, simple, and filiform; apical palpal solenidia $(\omega) 38$ (35-41) long, stout, and filiform; infracapitular setae $(m) 9$ (7-11) long, thick, and filiform.

Dorsum (Fig. 32). Idiosoma smooth, without any sculpture. Both anterior and posterior margins of propodosoma concaved. Dorsosejugal region smooth, tight laterally, and wide medially. A pair of oval cupules ia situated laterally between setae c1 and $c 3$ and a pair of oval cupules im placed posterior to setae $d 3$, cupules ip invisible. All idiosomal setae are slightly thick and hook-like. Internal vertical setae $v i 13$ (11-15), external ones $v e$ invisible. Measurements of idiosomal setae are presented in Table (1).

Venter (Fig.34). Apodemes I approximately thin, located posterior to infracapitulum of gnathosoma, jointed at the middle to form a "Y-shaped" sternum, the latter long but free posteriorly; anterior apodemes II extending postero-medially but not fused posteriorly; posterior apodemes II 
long fused posteriorly but not fused with anterior ones; anterior apodemes of coxal field III long, fused medially, the posterior ones free anteriorly; anterior apodemes of coxal field IV fused medially and to longitudinal posterior sternal apodeme, the latter long fused anteriorly, thus coxal fields I, II, III open, coxal field IV closed. Coxal fields I and III, each with normal circular discs $(l a, 3 b)$ and coxal fields IV with the largest ones ( $4 a$ ) and small alveoli $(3 a)$ located medially on the end of posterior apodemes III; genital setae $(g) 7$ (6-82) long, positioned anterior and medial to $4 a$. Adhering plate (Fig. 35), 34 (32-36) long, 33 (31-
35) wide, normal-developed, entirely filling a space between legs IV, positioned on more distant far from posterior body margin; central suckers large approximately circular, with broad margin surrounded a pair of small suckers, anterior suckers smaller than central ones, approximately oblong, consisting of broad sclerotized margin surrounding a normal disc. Lateral and posterior suckers normal-developed. The ventral side is ornamented with heavy punctuate. Away from suckers, adhering plate internally punctuated.

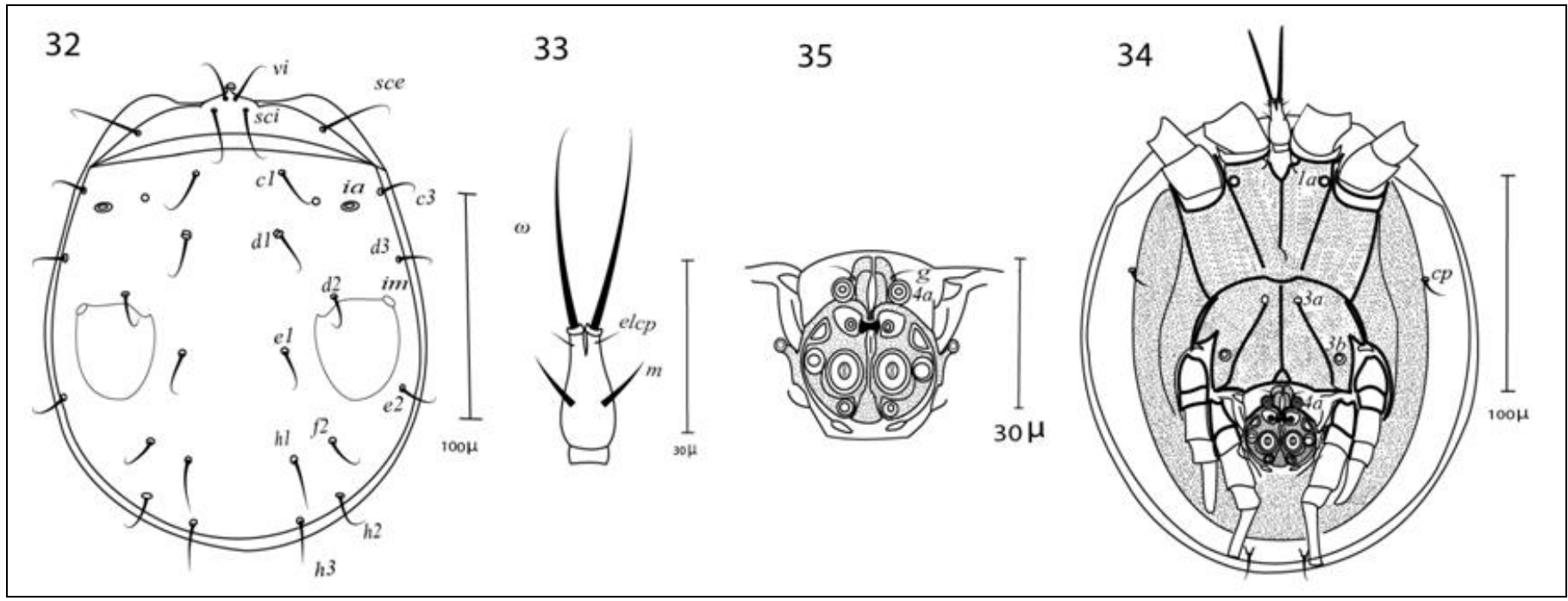

Figures (32-35). Acotyledon hookisetoses sp. nov. (deutonymphal male): 32. Dorsal view; 33. Gnathosoma; 34. Ventral view; 35. Adhering plate.

Legs (Figs. 36-39). All legs with well-developed hooked empodial claws, arising apically. Length of legs: legs I 75 (72-80), legs II 67 (63-71), legs III 77 (66-88), legs IV 75 (70-80). Trochanters I, II, and III each with filiform setae ( $p R \mathrm{I}$, pR II, $s R$ III). Femoral setation: 1-1-0-1, setae $v F$ I, $v F$ II and $w F$ IV, filiform. Genual setation: $2(\sigma)-2(\sigma)-1-0$; setae $c G$ I and II, both spine-like, setae $m G$ I, II and $n G$ III filiform, $\sigma$ on genua I long, longer than $\sigma$ of genua II, both filiform. Tibial setation: $2(\varphi)-2(\varphi)$ $1(\varphi)-1(\varphi)$; setae $g T, h T$ legs I and II, spine-like; setae $k T$ legs III short, but long on legs IV, both filiform; $\varphi$ of legs I-IV, filiform, very long on both legs I and II. Tarsal setation: $7(\omega 1, \omega 2)-6(\omega)-6-7$. Setae $q$ of tarsi I calceiform, of tarsi II uncate, of tarsi III clavate and of tarsi IV calceiform; setae $e$ of tarsi I, with crescent-like apices, of tarsi IV setae $e$ calceiform. The rest setae of tarsi I-IV, filiform. Solenidia $\omega 1$ long and clavate, $\omega 2$ short and tapering (tarsi I), $\omega$ (tarsi II), long and clavate, but shorter than $\omega l$ of tarsi I; $\varepsilon$ tarsi I and II, absent. Measurements of leg setation (I-IV) are presented in Table (2).

Examination of deutonymphs led to the discovery of external characteristics of which the sex of deutonymphs may be distinguished in the new species. On the dorsum, all dorsal setae of deutonymphal females longer but thinner than those of deutonymphal males; ventral side of deutonymphal females smooth, without any sculpture, except the adhering plate, while in deutonymphal males, ventral side ornamented with heavy punctuate; tarsi of legs III of deutonymphal males with a pair of clavate setae, in addition to a pair of calceiform setae on tarsi of legs IV, all setae on tarsi of legs III and IV, filiform in deutonymphal females, in addition to the body size and the length of leg chaetotaxy. 
Table 2. Measurements of leg setation of Acotyledon hookisetoses sp. $\mathrm{n}$. (deutonymphal stages, $\mathrm{n}=6$ ).

\begin{tabular}{|c|c|c|c|c|c|c|c|c|c|c|c|}
\hline $\begin{array}{c}\text { Legs } \\
\text { I }\end{array}$ & Dt. female & Dt. male & $\begin{array}{c}\text { Legs } \\
\text { II }\end{array}$ & Dt. female & Dt. male & $\begin{array}{c}\text { Legs } \\
\text { III }\end{array}$ & Dt. female & Dt. male & $\begin{array}{c}\text { Legs } \\
\text { IV }\end{array}$ & Dt. female & Dt. male \\
\hline$p R$ & $20(18-22)$ & $14(13-15)$ & $p R$ & $16(15-17)$ & $8(7-9)$ & $s R$ & $23(24-25)$ & $13(12-14)$ & $w F$ & $26(24-28)$ & $14(13-15)$ \\
\hline$v F$ & $28(26-30)$ & $23(22-24)$ & $v F$ & $21(18-24)$ & $16(15-17)$ & $n G$ & $20(19-21)$ & $8(7-9)$ & $k T$ & $13(12-14)$ & $15(13-17)$ \\
\hline$m G$ & $8(7-9)$ & $5(4-6)$ & $m G$ & $5(4-6)$ & $4(3-5)$ & $k T$ & $13(12-14)$ & $6(5-7)$ & & & \\
\hline$c G$ & $21(18-24)$ & $15(13-17)$ & $c G$ & $15(14-16)$ & $10(9-11)$ & $w$ & $14(12-16)$ & $19(17-21)$ & $w$ & $44(42-46)$ & $46(44-48)$ \\
\hline$g T$ & $12(10-14)$ & $19(17-21)$ & $g T$ & $10(8-12)$ & $16(15-17)$ & $r$ & $16(15-17)$ & $13(12-14)$ & $r$ & $14(13-15)$ & $13(12-14)$ \\
\hline$h T$ & $24(23-25)$ & $9(7-11)$ & $h T$ & $25(24-26)$ & $8(7-9)$ & $d$ & $15(13-17)$ & $8(7-9)$ & $d$ & $17(16-18)$ & $33(31-35)$ \\
\hline$r a$ & $25(19-31)$ & $16(15-17)$ & $r a$ & $17(15-19)$ & $8(7-9)$ & $p$ & $14(12-16)$ & - & $p$ & $23(21-25)$ & - \\
\hline$l a$ & $21(20-22)$ & $22(19-25)$ & $l a$ & $12(11-13)$ & $11(10-12)$ & $s$ & $15(13-17)$ & - & $s$ & $21(20-22)$ & $6(5-7)$ \\
\hline$f$ & $12(13-14)$ & $9(8-10)$ & $f$ & $7(6-8)$ & - & $q$ & $18(16-20)$ & $14(13-15)$ & $q$ & $17(16-18)$ & $18(17-19)$ \\
\hline$d$ & $17(14-20)$ & $17(14-20)$ & $d$ & $23(21-25)$ & $16(15-17)$ & $f$ & $14(13-15)$ & $12(11-13)$ & $f$ & $11(10-12)$ & $15(14-16)$ \\
\hline$q$ & $19(17-21)$ & $17(16-18)$ & $q$ & $23(22-24)$ & $19(16-22)$ & $e$ & $27(26-28)$ & $13(12-14)$ & $e$ & $21(1923)$ & $14(12-16)$ \\
\hline$p$ & $16(15-17)$ & $16(15-17)$ & $p$ & $17(16-18)$ & $14(12-16)$ & $\varphi$ & $23(21-25)$ & $23(21-25)$ & $\varphi$ & $12(11-13)$ & $9(7-11)$ \\
\hline$e$ & $27(21-33)$ & $23(22-24)$ & $e$ & $30(28-32)$ & $13(12-14)$ & & & & & & \\
\hline$\omega 1$ & $14(12-16)$ & $13(12-14)$ &. & & & & & & & & \\
\hline$\omega 2$ & $5(4-6)$ & $4(3-5)$ & $\omega$ & $7(6-8)$ & $8(7-9)$ & & & & & & \\
\hline$\varphi$ & $58(53-63)$ & $43(40-46)$ & $\varphi$ & $45(43-47)$ & $32(30-34)$ & & & & & & \\
\hline$\sigma$ & $20(17-23)$ & $14(12-16)$ & $\sigma$ & $10(9-11)$ & $4(3-5)$ & & & & & \\
\hline$D$
\end{tabular}

Dt.= Deutonymphal

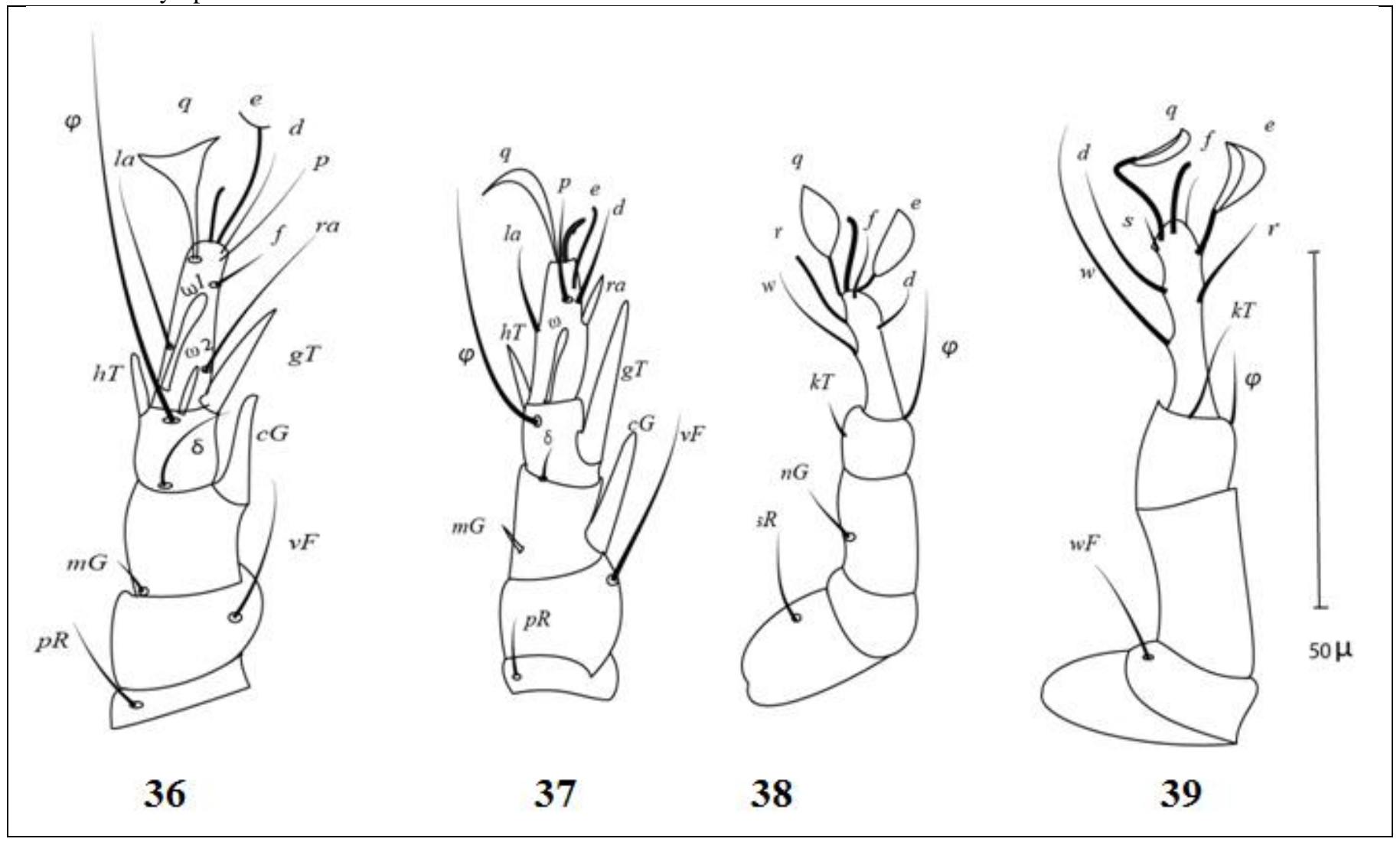

Figures (36-39). Acotyledon hookisetoses sp. nov. (deutonymphal male): 36. Leg I; 37. Leg II; 380. Leg III; 39. Leg IV. 
While most of the remaining morphological characteristics are completely identical between them.

Type material. Holotype and five paratypes of each stage (adult female, adult male, deutonymphal female, and deutonymphal male) collected by Dr. Azza A. Mohamed, 20 August 2020 from the colony of $S$. cerealella reared on wheat grains as a factitious host of the parasitoid, $T$ evanescens Westwood, 1833 (Hymenoptera: Trichogrammatidae), in Bio-Lab-Shandaweel of PPRI, ARC, Sohag, Egypt. Holotype and two paratypes of each stage (adult female, adult male, deutonymphal female, and deutonymphal male) are deposited in the Acari collection of Plant Protection Department, Faculty of Agriculture, Assiut University, Assiut 71526 Egypt, and three paratypes from each stage are deposited in the Acari collection of Plant Protection Research Institute, Shandaweel, Sohag, Egypt.

\section{Etymology}

The species name refers to the shape of dorsal setae.

\section{Remarks}

The deutonymph of the present species is closely related to Acotyledon arushensis Mahunka, 1961and Acotyledon limbata Mahunka, 1974, especially in the shape of dorsal setae. However, it differs from both species by the shape of gnathosoma, apodemes of coxal fields I and II, and the chaetotaxy of legs I-IV. The adult stages of $A$. arushensis and A. limbata are unknown.

\section{REFERENCES}

Ashfaq M, Chaudhri WM. 1986. Eight new hypopi of the genus Acotyledon Oud. from Pakistan (Acari: Acaridae). Pakistan Entomologist, 8(1-2): 1-28.

Ashfaq M, Sher F. 2002. Description of two new species (hypopi) of the genus Acotyledon Oudemans, 1903 (Acari: Acaridae) from Pakistan. Pakistan Journal of Agriculture Science, 39(1): 38-46.

Ashfaq M, Sarwar M, Parvez A. 1998. A description of two new species (hypopi) of the genus Acotyledon (Acariformes: Acaridae) from Pakistan. Acarina, 6: 51-57.

Eraky S. 1998. Mahunkaglyphus solimani gen. and sp. n. and three new species (Acari:
Astigmata) described from termite nests, Western desert, Egypt. Folia Entomologica Hungarica, 59: 241-250.

Eraky SA. 1999a. Five new hypopial nymphs (Acari: Acaridae and Histiostomatidae) described from different habitats. Folia Entomologica Hungarica, 60: 45-56.

Eraky SA 1999b. A new genus and three new species of mites (Acari: Acaridae) phoretic on termites infesting the camphor trees in Aswan, Egypt. Annales historica-naturales Museinationali shungarici, 91: 209-217.

Eraky SA, Osman MA. 2008. New identification key for some Acaridides mites (Acari: Acaridae) from Upper Egypt, with description of a new species. Acarines, 2: 49-60.

Eraky SA, Abdel-Aziz RM, Abo-Elmaged TM. 2020. Three new species of mites (Acari: Acaridae and Histiostomatidae) from manure and dunghills, Assiut, Upper Egypt. Egyptian Academic Journal of Biological Sciences, 12(2): 75-82.

Fain A, Philips JR. 1978. Astigmatic mites from nests of birds of prey in the U.S.A. IV. Description of the life cycle of Acotyledon paradoxa Oudemans, 1903. Zoologische Mededelingen, 53: 29-39.

Grandjean F. 1939. La chaetotaxy des patteschez les Acaridae. Bulletin de la Societe Zoologique de France, 64: 50-60.

Griffiths DA, Atyeo WT, Norton RA, Lynch CA. 1990. The idiosomal chaetotaxy of astigmatid mites. Journal of Zoology, 220: 1-32.

Honey SF, Sarwar ZM, Bashir MH, Ali S, Kamran M, Ashfaq M. 2014. Two new species of Acotyledon Oudemans, 1903 (Acari: Acaridae) infesting stored chickpea, Cicer arientinum from Pakistan. Pakistan Journal of Zoology, 46(2): 479-484.

Klimov PB. 2000. A review of acarid mites of the tribe Caloglyphini (Acaridae: Acariformes) with description of a new genus and species from Siberia and Russian Far East. Vestnik Zoologii. 34: 27-35.

Klimov PB, O’Connor BM. 2003. Phylogeny, historical ecology, and systematic of some mushroom-associated mites of the genus Sancassania (Acari: Acaridae), with new 
generic synonymies. Invertebrate Systematics, 17: 469-514.

Mahunka S. 1961.Wissenschaftlicheergebnisse der erstenzoologis chenexpendition in Ostafrika, 5. Acarina: Acaridae und Anoetidae. Annales historica-naturales Museination alishungarici, 53: 525-530.

Mahunka S. 1973. Auf Insekten Lebende Milben (Acari: Acarida, Tarsonemida) aus Africa II. Acta Zoologica Academiae Scientiarum Hungaricae, 19(3-4): 289-337.

Mahunka S. 1974. Auf Insekten Lebende Milben (Acari: Acarida, Tarsonemida) aus Africa III. Acta Zoologica Academiae Scientiarum Hungaricae, 20(1-2): 137-154.

Mahunka S. 1978. Schizoglyphidae fam. N and new taxa of Acaridae and Anoetidae
(Acari: Acarida). Acta Zoologica Academiae Scientiarum Hungaricae, 24(12): 107-131.

Oudemans AC. 1903. Notes on Acari. Tijkdschrift Voor Entomologie. 45: 147.

Samsinak K. 1966. Die Neuerrichtung der Gattung Cosmoglyphus Oudemans, 1932, gleichzeitigein Beitragzum problem der "Copra Itch". Zoologischer Anzeiger Journal. 176: 27-42.

Samsinak K. 1968. A new acaridoid mite, Acotyledon palaeorhizae n. sp. Pacific Insects, 10: 271-273. 